Edubiotik: Jurnal Pendidikan, Biologi dan Terapan
ISSN 2528-679X (print), ISSN 2597-9833 (online)
Volume 5, Nomor 02, Tahun 2020, Hal. 103-113
Available online at:
http:I/ejurnal.budiutomomalang.ac.id/index.php/edubiotik

Research Article

OPEN ACCESS

\title{
Aplikasi blood smart: Media pembelajaran biologi berbasis android di era revolusi industri 4.0
}

\author{
Nurul Asikin*, Nevrita, Wihelmina Noni
}

Pendidikan Biologi, Universitas Maritim Raja Ali Haji, Tanjungpinang, Indonesia

Email: nurul_asikin@umrah.ac.id*, nevrita@umrah.ac.id, wihelminanoni07@gmail.com

\begin{tabular}{|c|c|}
\hline Informasi Artikel & ABSTRACT \\
\hline $\begin{array}{l}\text { Submit: } 20-06-2020 \\
\text { Diterima: } 08-11-2020 \\
\text { Dipublikasikan: } 09-11-2020\end{array}$ & $\begin{array}{l}\text { The learning media based on android for biology have not been used optimally in } \\
\text { the era of the industrial revolution 4.0. The research objective was to determine } \\
\text { the feasibility of blood smart applications as a learning media based on android } \\
\text { for biology in the era of the industrial revolution 4.0. The type of research used is } \\
\text { research and development with the Thiagarajan Four-D model which includes } \\
\text { define, design and develop. The research instrument used a material expert } \\
\text { questionnaire, media expert, teacher practicality questionnaire, and student } \\
\text { practicality questionnaire given to } 30 \text { students. The research data is qualitative in } \\
\text { the form of suggestions and comments from experts and teachers which are } \\
\text { analyzed descriptively, while quantitative data is processed into interval data } \\
\text { using a Likert scale.The results showed that the blood smart application was } \\
\text { declared valid in the media aspect (95.2\%), the material aspect (87.5\%). The } \\
\text { practicality of the blood smart application by the teacher was } 95 \% \text { (very practical } \\
\text { criteria), and the practicality by students was } 91.8 \% \text { (very practical criteria). Thus, } \\
\text { the blood smart application is suitable for use as a learning media based on } \\
\text { android for biology in the era of the industrial revolution } 4.0 \text {. } \\
\text { Key words: Android; blood smart; learning media }\end{array}$ \\
\hline Penerbit & ABSTRAK \\
\hline $\begin{array}{l}\text { Program Studi Pendidikan Biologi } \\
\text { IKIP Budi Utomo, Malang, Indonesia }\end{array}$ & $\begin{array}{l}\text { Media pembelajaran biologi berbasis android belum digunakan secara optimal di } \\
\text { era revolusi industri } 4.0 \text {. Tujuan penelitian untuk mengetahui kelayakan aplikasi } \\
\text { blood smart sebagai media pembelajaran biologi berbasis android di era revolusi } \\
\text { industri 4.0. Jenis penelitian yang digunakan yaitu penelitian dan pengembangan } \\
\text { (reseacrh and development) dengan model Four-D Thiagarajan yang meliputi } \\
\text { define, design, dan develop. Instrumen penelitian menggunakan angket ahli } \\
\text { materi, ahli media, angket kepraktisan guru, dan angket kepraktisan siswa yang } \\
\text { diberikan kepada } 30 \text { siswa. Data penelitian adalah data kualitatif berupa saran } \\
\text { dan komentar dari para ahli dan guru yang dianalisis secara deskriptif, sedangkan }\end{array}$ \\
\hline 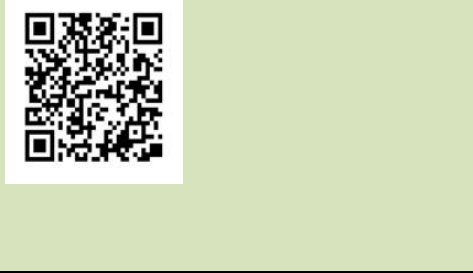 & $\begin{array}{l}\text { data kuantitatif diolah menjadi data interval menggunakan skala Likert. Hasil } \\
\text { penelitian menunjukkan bahwa aplikasi blood smart dinyatakan valid pada aspek } \\
\text { media (95,2\%), aspek materi (87,5\%). Kepraktisan aplikasi blood smart oleh guru } \\
\text { sebesar } 95 \% \text { (kriteria sangat praktis), dan kepraktisan oleh siswa sebesar } 91,8 \% \\
\text { (kriteria sangat praktis). Dengan demikian, aplikasi blood smart layak digunakan } \\
\text { sebagai media pembelajaran biologi berbasis android di era revolusi industri } 4.0 \text {. } \\
\text { Kata kunci: Android; blood smart; media pembelajaran }\end{array}$ \\
\hline
\end{tabular}

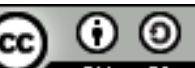

This Edubiotik : Jurnal Pendidikan, Biologi dan Terapan is licensed under a CC BY-SA (Creative Commons AttributionShareAlike 4.0 International License) 


\section{PENDAHULUAN}

Perkembangan teknologi kini semakin pesat, yang dikenal dengan revolusi industri 4.0. Revolusi industri 4.0 telah masuk di segala bidang kehidupan termasuk bidang pendidikan (Muhaimin et al., 2019; Prasojo et al., 2017). Perkembangan ini menuntut dunia pendidikan untuk mengintegrasikan teknologi agar dapat mempermudah aktivitas pembelajaran. Teknologi kini memberikan fasilitas yang serba canggih pada guru untuk mengembangkan media pembelajaran dengan memanfaatkan teknologi yang telah ada seperti media pembelajaran berbasis website dan android (Aprilia, Wijaya, \& Suryadi, 2014; Nazar, Putri, \& Puspita, 2020).

Android menjadi salah satu produk aplikasi dari perkembangan teknologi canggih yang membuat setiap pengguna merasa kecanduan untuk mengaksesnya secara terus menerus. Proses akses ini dapat dilakukan melalui smartphone yang dimiliki sehingga manfaat android kini telah digunakan oleh setiap kalangan (Kustandi, C. \& Sutjipto, 2013; Kuswanto \& Radiansah, 2018). Baik itu kalangan pekerja, mahasiswa maupun pelajar semuanya memanfaatkan android untuk memudahkan segala kebutuhannya. Kecanggihan android mampu memfasilitasi layanan jasa seperti pemesanan transportasi, jasa travel, belanja online, pemesanan makanan online, belajar jarak jauh serta dapat mengganti peran dari produk-produk lainnya. Oleh karena itu, penggunaan android telah memudahkan setiap kalangan agar tidak perlu bertransaksi secara langsung dalam memenuhi segala kebutuhan penggunanya (Kuswanto \& Radiansah, 2018; Yektyastuti \& Ikhsan, 2016).

Android dapat digunakan sebagai salah satu inovasi dalam proses pembelajaran. Smartphone android bisa digunakan untuk alternatif media pembelajaran sehingga dapat meningkatkan pemahaman siswa terhadap suatu materi (Sadikin, 2019). Siswa dapat memperoleh pemahaman tanpa ada batasan ruang dan waktu karena materi pelajaran dapat diakses dengan mudah dengan menggunakan smartphone android (Kustandi, C. \& Sutjipto, 2013; Nazar et al., 2020; Ahmed et al., 2020). Oleh sebab itu, guru dapat memanfaatkan kecanggihan teknologi seperti smartphone android untuk menunjang proses pembelajaran (Prasojo et al., 2017; Sadikin, 2019; Yektyastuti \& Ikhsan, 2016). Smartphone android bisa dimanfaatkan sebagai mobile learning.

Mobile learning merupakan salah satu alternatif untuk mengembangkan media pembelajaran yang memanfaatkan perangkat dan teknologi komunikasi bergerak sehingga dapat melengkapi kegiatan pembelajaran serta memberikan siswa peluang untuk mempelajari kembali materi terkait kapanpun dan dimanapun siswa berada. Hal ini sebagai solusi untuk menghadapi dunia pendidikan di era revolusi industri 4.0 Pengetahuan saat ini sudah bisa ditransformasikan ke dalam teknologi sehingga memudahkan guru untuk mengatasi keterbatasan yang ada seperti keterbatasan ruang dan waktu. Pemanfaatan teknologi dapat dimanfaatkan dalam proses pembelajaran. Salah satu contoh pemanfaatan teknologi berupa tersedianya aplikasi-aplikasi yang dapat digunakan sebagai media pembelajaran (Asikin, 2016; Asikin, 2018b).

Aplikasi pembelajaran yang tersedia dan mudah diakses dengan menggunakansmartphone dapat disebut mobile learning. Cukup banyak aplikasi pembelajaran yang telah tersedia di play store, namun rata-rata aplikasi tersebut menampilkan ringkasan materi secara keseluruhan. Oleh karena itu, pada penelitian ini perlu dikembangkan sebuah media pembelajaran biologi berupa aplikasi android yang bisa diakses melalui smartphone (Nazar et al., 2020). Aplikasi pembelajaran yang dikembangkan tidak hanya menyajikan ringkasan materi tetapi tersedia gambar, animasi menarik, video pembelajaran terkait materi, dan glosarium. Penyajian ini dapat memudahkan siswa dalam mempelajari dan mengulang materi yang belum dipahami sehingga pembelajaran menjadi lebih efektif. Media pembelajaran sangat efektif untuk meningkatkan hasil belajar siswa sehingga media merupakan salah 
satu aspek penting dalam mendukung proses pembelajaran (Asikin, 2018a; Sadikin, 2019; Almara'beh, Amer, \& Sulieman, 2016; Amna, Wirasasmita, \& Fathoni, 2018).

Hasil observasi pada pembelajaran biologi di SMPS Maitreyawira Tanjungpinang menunjukkan bahwa media pembelajaran biologi yang tersedia dan dapat digunakan oleh guru meliputi gambar, torso, video pembelajaran, dan penggunaan proyektor. Namun media yang digunakan masih memiliki keterbatasan tersendiri. Salah satunya ketersediaan proyektor di sekolah, masih terbilang sedikit sehingga untuk menggunakannya dalam pembelajaran sangat terbatas (Nevrita, Asikin, \& Amelia, 2020). Guru hanya menggunakan gambar, torso dan buku paket untuk menyampaikan isi pembelajaran (Evriyanti, Muhartati, \& Irawan, 2019). Kondisi keterbatasan media pembelajaran dan kurangnya variasi ini, menuntut perlunya sebuah pengembangan produk media pembelajaran biologi agar permasalahan di atas dapat terselesaikan.

Produk media pembelajaran biologi yang dikembangkan dalam penelitian ini berupa aplikasi blood smart yang dapat dioperasikan menggunakan smartphone dengan sistem operasi android tanpa terbatas oleh ruang dan waktu. Aplikasi blood smart ini didesain dengan menggunakan software Unity 3D yang berbeda dengan penelitian sebelumnya yaitu menggunakan software adobe flash (Hidayati \& Irmawati, 2019; Prayitno \& Hidayati, 2017). Aplikasi blood smart memuat materi pelajaran biologi tentang sistem peredaran darah manusia, gambar, video, dan animasi yang menarik sehingga mudah dipahami oleh siswa. Aplikasi blood smart juga perlu dilengkapi dengan petunjuk penggunaan sehingga memudahkan guru maupun siswa dalam mengaksesnya. Media pembelajaran yang efektif dan praktis adalah media pembelajaran yang mampu membantu siswa dalam memahami materi (Kuswanto \& Radiansah, 2018; Nazar et al., 2020). Berdasarkan uraian di atas, tujuan penelitian ini adalah untuk mengetahui kelayakan aplikasi blood smart sebagai media pembelajaran biologi berbasis android di era revolusi industri 4.0 .

\section{METODE PENELITIAN}

Jenis penelitian adalah penelitian dan pengembangan (research and development). Model penelitian dan pengembangan yang digunakan adalah model four-D Thiagarajan. Tahapan model four$D$ Thiagarajan, yaitu define (pendefinisian), design (desain), develop (pengembangan) dan disseminate (penyebarluasan). Akan tetapi, pada penelitian ini tidak melaksanakan tahap disseminate (penyebarluasan) dikarenakan keterbatasan waktu dalam penelitian.

Tahap pendefinisian yang dilakukan adalah melakukan analisis kebutuhan terdiri dari analisis permasalahan dalam pembelajaran, analisis kurikulum, analisis tujuan pembelajaran, analisis kebutuhan media, dan analisis karakteristik siswa. Tahap desain dilakukan untuk merancang aplikasi blood smart yang dikembangkan terdiri dari pembuatan desain media (storyboard), penyusunan soal dan jawaban, serta menentukan gambar, tombol, background dan font untuk dimuat dalam aplikasi yang diperoleh dari mengunduh berbagai sumber di internet. Aplikasi blood smart didesain dengan menggunakan software Unity 3D. Software Unity 3D memiliki kelebihan dibanding software lainnya yaitu memiliki tools dan library lebih lengkap, mendukung berbagai platform (android, PC, dan lain-lain), memilik lisensi gratis dan mendukung format dua dimensi (2D) dan tiga dimensi (3D).

Desain aplikasi blood smart juga menggunakan software corel draw untuk mendesain tampilan aplikasi, seperti warna background serta penggunaan backsound, gambar, icon dan jenis font serta video yang diperoleh dari media internet. Tahap pengembangan yaitu melaksanakan validasi aplikasi blood smart oleh validator. Validator berperan sebagai pemberi kritik dan saran pada aplikasi yang dikembangkan sehingga dapat diketahui tingkat validitasnya. Validator terdiri dari ahli media dan ahli 
materi. Selanjutnya dilakukan uji coba kepraktisan aplikasi blood smart pada guru dan siswa. Uji coba kepraktisan aplikasi blood smart menggunakan 30 siswa kelas VIII E SMPS Maitreyawira Tanjungpinang. Uji coba ini dilakukan untuk melihat kepraktisan aplikasi blood smart yang dikembangkan sebagai media pembelajaran biologi. Hasil perbaikan atau revisi atas kritik dan saran yang diperoleh dari uji validasi dan uji coba kepraktisan menentukan penyempurnaan dari aplikasi blood smart agar memenuhi kriteria valid sehingga dapat digunakan pada pembelajaran biologi. Alur penelitian pengembangan blood smart sebagai media pembelajaran biologi dapat dilihat pada Gambar 1.

Instrumen penelitian yang digunakan pada penelitian sebagai berikut. (1) Lembar observasi pengamatan permasalahan dalam pembelajaran biologi di SMPS Maitreyawira Tanjungpinang. (2) Angket validasi ahli media untuk melakukan validasi pada aspek media aplikasi blood smart. (3) Angket validasi ahli materi untuk memvalidasi aplikasi blood smart pada aspek materi. (4) Angket kepraktisan guru dan siswa digunakan untuk mengetahui tingkat kepraktisan aplikasi blood smart yang telah dikembangkan.

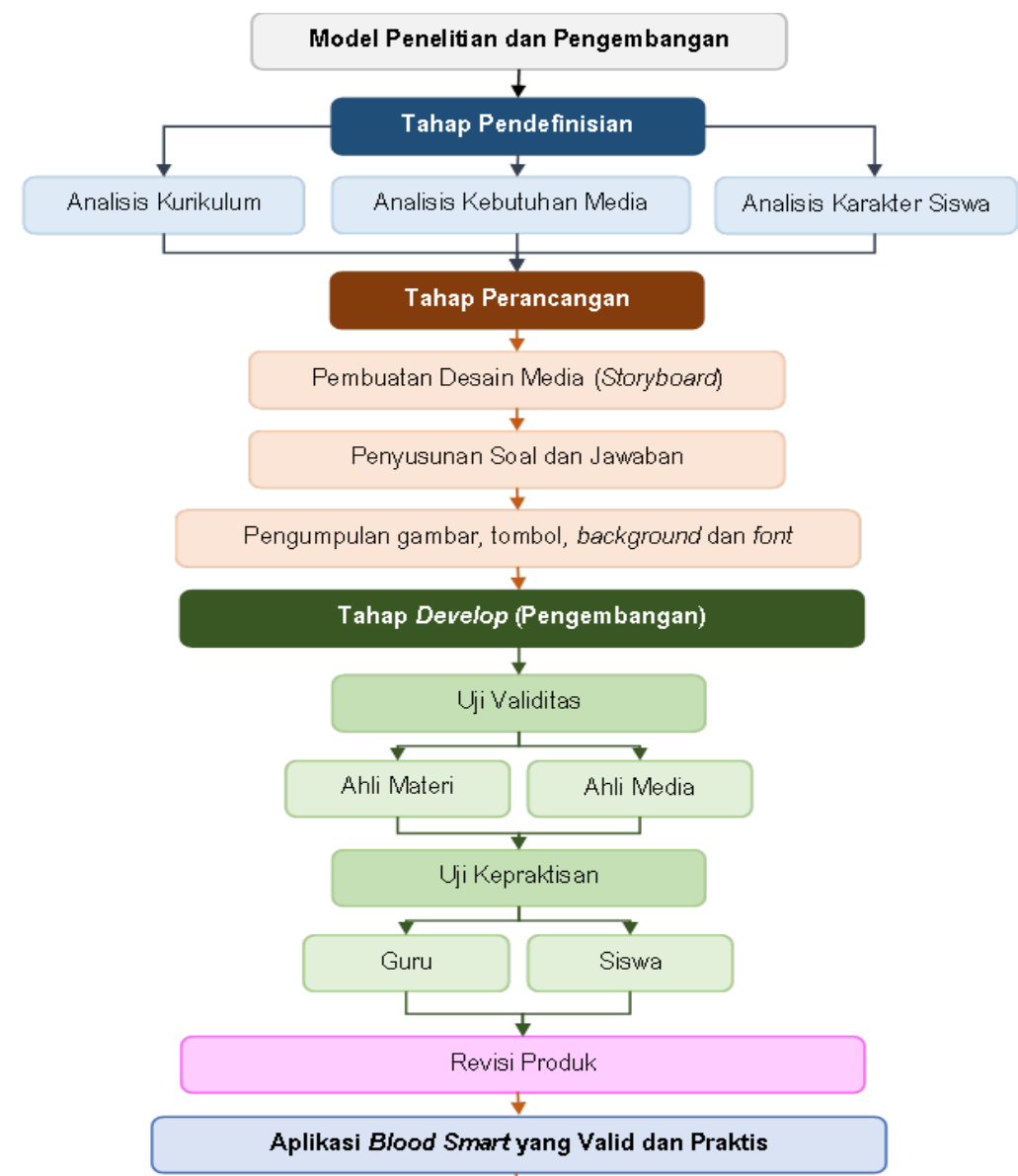

Gambar 1. Alur PenelitianPengembangan Aplikasi Blood Smart Sebagai Media Pembelajaran Biologi

Data yang dikumpulkan dalam penelitian ini terdiri dari dua data, yaitu data kuantitatif dan data kualitatif. Data kuantitatif merupakan data skor penilaian yang diperoleh dari angket validitas oleh ahli media dan materi serta angket kepraktisan guru dan siswa. Data kualitatif berupa kritik dan saran dari para validator dan hasil ujicoba kepraktisan yang digunakan untuk penyempurnaan dari aplikasi bood smart sebagai media pembelajaran biologi.Data penelitian dianalisis secara deskriptif. Hasil analisis disesuaikan dengan kriteria kevalidan dan kepraktisan (Rusdi, 2018). Kriteria kevalidan dan kepraktisan produk pengembangan dapat dilihat pada Tabel 1 dan Tabel 2. 
Tabel 1. Kriteria Kevalidan Produk Pengembangan

\begin{tabular}{|c|c|c|}
\hline Rentang Nilai Kevalidan (\%) & Kriteria & Kesimpulan \\
\hline $\begin{array}{r}82-100 \\
63-81 \\
44-62 \\
25-43\end{array}$ & $\begin{array}{l}\text { Sangat Valid } \\
\text { Valid } \\
\text { Kurang Valid } \\
\text { Tidak Valid }\end{array}$ & $\begin{array}{l}\text { Produk dapat digunakan tanpa revisi } \\
\text { Produk dapat digunakan dengan sedikit revisi } \\
\text { Produk dapat digunakan dengan banyak revisi } \\
\text { Produk masih perlu konsultasi secara intensif }\end{array}$ \\
\hline$\frac{\text { abel 2. Kriteria Kepraktisan Pro }}{\text { Rentang Nilai Kepraktisan (\%) }}$ & $\frac{\text { engembangan }}{\text { Kriteria }}$ & Kesimpulan \\
\hline $\begin{array}{r}82-100 \\
63-81 \\
44-62 \\
25-43\end{array}$ & $\begin{array}{l}\text { Sangat Praktis } \\
\text { Praktis } \\
\text { Kurang Praktis } \\
\text { Tidak Praktis }\end{array}$ & $\begin{array}{l}\text { Produk dapat digunakan tanpa revisi } \\
\text { Produk dapat digunakan dengan sedikit revisi } \\
\text { Produk dapat digunakan dengan banyak revisi } \\
\text { Produk masih perlu konsultasi secara intensif }\end{array}$ \\
\hline
\end{tabular}

\section{HASIL PENELITIAN DAN PEMBAHASAN}

Hasil tahap define (pendefinisian) menunjukkan bahwa ditemukan beberapa permasalahan pada pembelajaran biologi di SMPS Maitreyawira Tanjungpinang. Media pembelajaran biologi belum variatif dan belum memanfaatkan teknologi digital. Pembelajaran biologi membutuhkan media pembelajaran yang mampu menggambarkan materi biologi secara konkrit dan faktual agar siswa mudah memahami konsep materi biologi. Pembelajaran biologi membutuhkan media pembelajaran berbasis android agar siswa dapat mengakses materi biologi dimanapun dan kapanpun mereka inginkan melalui smartphone yang dimiliki.

Hasil tahap design menunjukkan bahwa aplikasi blood smart didesain dengan menggunakan software Unity 3D karena software ini memiliki kelebihan yaitu memiliki tools dan library lebih lengkap, mendukung berbagai platform (android, PC, dan lain-lain), memilik lisensi gratis dan mendukung format dua dimensi (2D) dan tiga dimensi (3D). Aplikasi blood smart juga dikembangkan dengan menggunakan software corel draw untuk mendesain tampilan aplikasi, seperti warna background, gambar, icon dan jenis font yang diperoleh dari media internet. Pemilihan warna background yang tepat dalam aplikasi blood smart ini sangat penting dilakukan untuk menarik perhatian dan memberikan motivasi belajar bagi siswa. Oleh karena itu, pemilihan warna yang tepat sangat diperlukan bagi pengembangan media pembelajaran (Pranata, Santyadiputra, \& Sindu, 2017).

Selain itu, pada aplikasi blood smart ditambahkan backsound music agar lebih menarik dan membuat rileks siswa dalam memahami kosep materi yang disediakan. Gambar, icon, dan jenis font pada aplikasi blood smart digunakan untuk mendukung materi pelajaran. Gambar, icon, dan jenis font tersebut diperoleh dari media internet www.google.com, www.freepik.com, dan www.fontawesome.com. Penggunaan gambar pada aplikasi blood smart membantu siswa dalam memahami materi pelajaran. Selain itu, video pembelajaran juga ditambahakan pada aplikasi blood smart agar lebih mempermudah siswa dalam memahami konsep materi pelajaran. Video pembelajaran tentang sistem peredaran darah pada manusia diperoleh dari www.youtube.com. Nama blood smart pada aplikasi ini dipilih karena telah menggambarkan keseluruhan isi yang membahas materi sistem peredaran darah manusia. Aplikasi blood smart memuat kata pengantar, petunjuk penggunaan, memuat petunjuk; kompetensi siswa (kompetensi inti, kompetensi dasar, indikator dan tujuan pembelajaran) berdasarkan kurikulum 2013, materi sistem peredaran darah pada manusia, video pembelajaran, kuis pilihan ganda, glosarium (kata atau istilah yang berhubungan dengan materi pelajaran), daftar pustaka, dan profil pengembang aplikasi. Aplikasi blood smart dapat dioperasikan dengan smartphone berbasis android karena berformat APK dengan kapasitas 58 MB. Beberapa tampilan pada aplikasi blood smart seperti tampilan awal, menu petunjuk, menu kompetensi dan menu video dapat dilihat pada Gambar 2 dan Gambar 3. 
Hasil tahap develop (pengembangan) menunjukkan bahwa aplikasi blood smart sebagai media pembelajaran biologi yang telah dikembangkan memenuhi kriteria valid dan praktis. Hasil validasi aplikasi blood smart oleh ahli media dan ahli materi dapat dilihat pada Tabel 3. Hasil penilaian kepraktisan aplikasi blood smart oleh guru dapat dilihat pada Tabel 4. Hasil penilaian kepraktisan blood smart oleh siswa dapat dilihat pada Tabel 5.
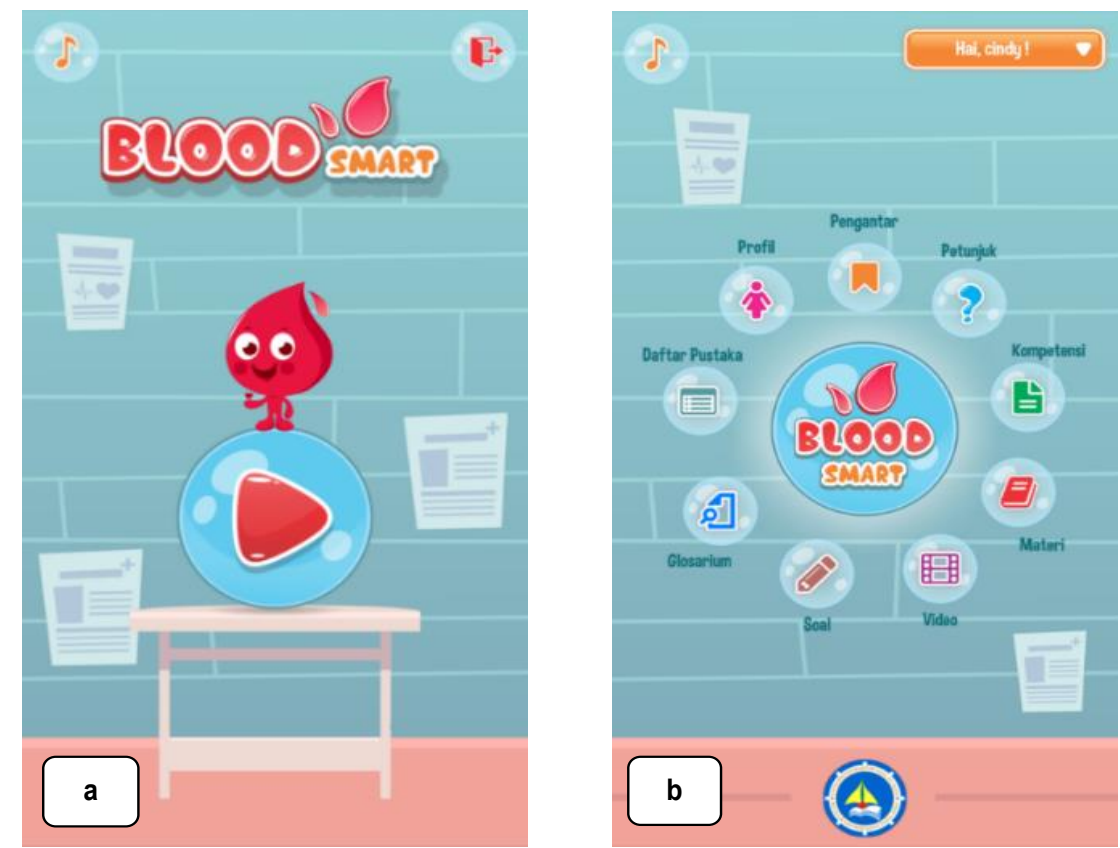

Gambar 2. (a) Tampilan Awal; (b) Tampilan Menu Petunjuk (Sumber: Dokumentasi Pribadi, 2020)
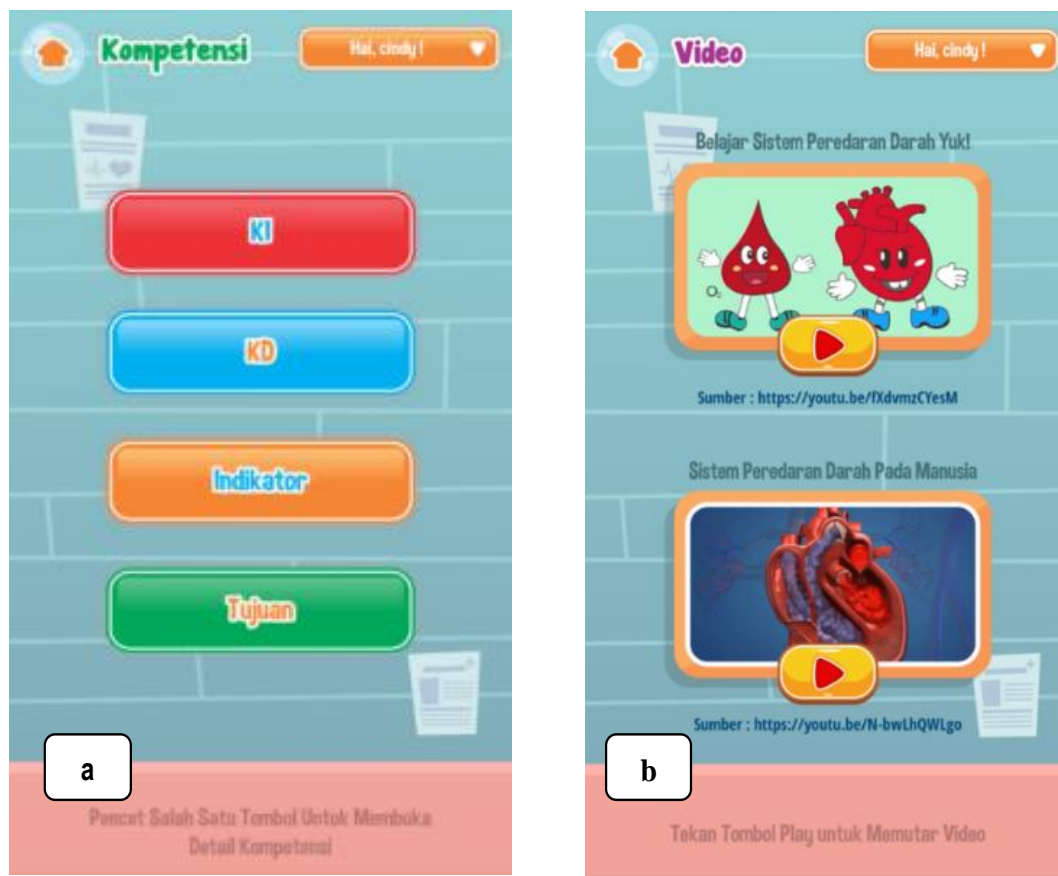

Gambar 3. (a) Tampilan Menu Kompetensi, (b) Tampilan Menu Video (Sumber: Dokumentasi Pribadi, 2020)

Tabel 3. Hasil Validasi Aplikasi Blood Smart oleh Ahli Media dan Ahli Materi

\begin{tabular}{ccccc}
\hline No. & Ahli & Aspek Penilaian & Nilai kevalidan (\%) & Kriteria \\
\hline 1 & Ahli Media & Aspek tampilan media (meliputi desain, pemilihan \\
& & 94,6 & Sangat Valid \\
\hline
\end{tabular}




\begin{tabular}{llll}
\hline & $\begin{array}{l}\text { font, keterbacaan gambar, kualitas video, efek } \\
\text { animasi dan suara) } \\
\text { Aspek pemograman (meliputi petunjuk penggunaan } \\
\text { aplikasi, tombol navigasi, navigasi halaman, materi } \\
\text { dan video) }\end{array}$ & 95,8 & Sangat Valid \\
$\begin{array}{l}\text { Rata-rata } \\
\mathbf{2} \text { Ahli Materi }\end{array}$ & $\begin{array}{l}\text { Aspek materi (meliputi kesesuaian materi dengan } \\
\text { silabus, KI, KD, indikator, tujuan pembelajaran, } \\
\text { keterkaitan materi dengan soal dan glosarium, } \\
\text { kejelasan gambar, video dan animasi) } \\
\text { Aspek penyajian materi (meliputi urutan isi materi, } \\
\text { kejelasan pembahasan materi, kejelasan petunjuk } \\
\text { penggunaan) }\end{array}$ & 87,5 & Sangat Valid \\
Rata-rata & & 87,5 & Sangat Valid \\
\hline
\end{tabular}

Tabel 3 menunjukkan bahwa validasi media terdiri daridua aspek yaitu aspek tampilan media dan aspek pemograman, sedangkan validasi materi terdiri dari aspek materi dan aspek penyajian materi. Ditinjau dari aspek tampilan media, media aplikasi blood smart dikategorikan sangat valid dengan nilai rata-rata kevalidan sebesar $94,64 \%$. Aspek tampilan media menurut ahli sudah baik dan sesuai dengan karakteristik siswa kelas VIII yaitu tampilan gambar, animasi dan video yang menarik perhatian siswa. Hal ini dikarenakan pada tampilan media yang dikembangkan telah memenuhi kriteria menarik seperti pemilihan warna, background, kualitas dari gambar dan video, backsound serta efek animasi yang berkaitan dengan materi yang disajikan. Pemilihan warna serta background disesuaikan dengan corak warna yang dominan terang, sehingga dapat menarik perhatian siswa pada aplikasi tersebut. Penggunaan warna yang sesuai dalam media pembelajaran dapat membangkitkan motivasi, perasaan, perhatian, dan kesediaan siswa dalam belajar (Riyanto \& Susilawati, 2019; Stamer et al., 2020).

Kualitas gambar dan video juga dinilai sudah baik karena sebelum disajikan sudah memilah gambar dan video yang kualitasnya baik sehingga tidak terlihat kabur maupun buram. Dengan demikian siswa dapat memahami materi melalui gambar dan video dengan jelas. Media gambar dan video yang dipilih untuk membuat animasi terkait dengan materi sistem peredaran darah memiliki kualitas yang bagus sehingga mempunyai tujuan untuk menarik perhatian, memperjelas materi, serta mengilustrasikan fakta dan informasi-informasi dalam media yang telah dikembangkan. Oleh karena itu, dalam aplikasi tersebut perlu disajikan gambar dan sekaligus video guna membantu siswa dalam memahami materi pelajaran (Asikin, 2018a; Kustandi, C. \& Sutjipto, 2013). Efek animasi yang disajikan yakni berkaitan dengan materi sistem peredaran darah guna menceritakan dan menjelaskan materi yang disampaikan. Penilaian ahli media terhadap kriteria ini sudah baik karena media animasi dapat memudahkan guru dalam menyampaikan materi pelajaran sekaligus memudahkan siswa dalam memahami konsep materi yang disampaikan oleh guru, sehingga dapat meningkatkan motivasi dan hasil belajar siswa (Prasojo et al., 2017; Riyanto \& Susilawati, 2019; Saputro \& Saputra, 2014).

Validasi oleh ahli materi berkaitan dengan dua aspek yakni aspek materi dan aspek penyajian materi. Aspek materi, aplikasi blood smart dikategorikan sangat valid dengan nilai rata-rata kevalidan sebesar $87,5 \%$. Aspek materi mengacu pada kesesuaian materi terhadap kompetensi inti, kompetensi dasar, indikator kompetensi dan tujuan pembelajaran serta keterkaitan soal evaluasi, glosarium dan gambar animasi terhadap materi. Selain itu, materi pelajaran menjadi penting dalam keberhasilan belajar siswa. Jika materi yang disajikan memuat konsep yang salah, maka akan menggagalkan siswa dalam belajar (Nevrita et al., 2020; Yektyastuti \& Ikhsan, 2016). Salah satu kriteria pemilihan media pembelajaran yang tepat adalah kesesuaian media dengan materi kurikulum dan tujuan pembelajaran (Arsyad, 2016; Kustandi, C. \& Sutjipto, 2013). Sehingga kegiatan belajar mengajar di kelas bisa berjalan baik dan tujuan pembelajaran dapat tercapai. Salah satu kriteria pemilihan media dalam proses pembelajaran adalah ketepatannya dengan tujuan pembelajaran dan isi bahan pengajaran sehingga lebih cepat dan mudah dipahami siswa (Asikin, 2018b; Wabula, Papilaya, \& Rumahlatu, 2020). 
Tabel 4. Hasil Penilaian KepraktisanAplikasi Blood Smart oleh Guru

\begin{tabular}{clcc}
\hline No. & \multicolumn{1}{c}{ Aspek Penilaian } & Nilai Kepraktisan (\%) & Kriteria \\
\hline 1 & Aspek Tampilan Media & 95 & Sangat Praktis \\
2 & Aspek Kemudahan Penggunaan & 100 & Sangat Praktis \\
3 & Aspek Bahasa & 100 & Sangat Praktis \\
4 & Aspek Materi & 75 & Praktis \\
Rata-rata & & 95 & Sangat Praktis \\
\hline
\end{tabular}

Tabel 4 menunjukkan rata-rata nilai kepraktisan oleh guru sebesar $95 \%$ dan dikategorikan sangat praktis. Namun, pada hasil penilian ditemukan bahwa nilai kepraktisan dari aspek materi lebih rendah dibandingkan dengan nilai kepraktisan pada aspek-aspek yang lain. Hal ini dikarenakan konsep materi yang termuat pada aplikasi blood smart masih perlu diperbaiki agar mencapai konsep materi yang benar. Kebenaran konsep materi menjadi hal yang sangat penting untuk diperhatikan karena kesalahan konsep materi yang disampaikan kepada siswa akan menyebabkan siswa gagal dalam belajar (Hidayati \& Irmawati, 2019; Hidayati, Pangestuti, \& Prayitno, 2019; Prayitno \& Hidayati, 2017; Hidayati, Irmawati, \& Prayitno, 2019).

Tabel 5. Hasil Penilaian Kepraktisan Blood Smart oleh Siswa

\begin{tabular}{clcc}
\hline No. & \multicolumn{1}{c}{ Aspek Penilaian } & Nilai Kepraktisan (\%) & Kriteria \\
\hline 1 & Aspek tampilan media & 91,3 & Sangat Praktis \\
2 & Aspek kemudahan penggunaan & 90,5 & Sangat Praktis \\
3 & Aspek bahasa & 95,8 & Sangat Praktis \\
4 & Aspek materi & 94,1 & Sangat Praktis \\
Rata-rata & & 91,8 & Sangat Praktis \\
\hline
\end{tabular}

Tabel 5 menunjukkan bahwa aplikasi blood smart dikategorikan sangat praktis untuk semua aspek penilaian. Hal ini terbukti dari rata-rata nilai kepraktisan sebesar $91,8 \%$ dan dikategorikan sangat praktis. Aspek kemudahan penggunaan memperoleh nilai persentase yang lebih rendah dibandingkan aspek yang lain. Hal ini dikarenakan siswa masih belum terbiasa dalam menggunakan aplikasi blood smart melalui smartphone yang mereka miliki, walaupun dalam aplikasi ini sudah tersedia petunjuk penggunaan. Aspek tampilan media yang disajikan dalam aplikasi sudah jelas dan mudah dipahami. Penilaian untuk aspek ini dapat dikatakan baik sesuai dengan perolehan skor yang diberi oleh guru maupun siswa. Seperti yang dikatakan Arsyad (2016) bahwa desain pada tampilan media menjadi ciri dan prinsip agar media pembelajaran harus mampu menyajikan visual yang dinamis. Sedangkan dari aspek kemudahan penggunaan yakni berkaitan dengan guru maupun siswa dalam menggunakan dan mengoperasikan aplikasi blood smart, perolehan nilai untuk aspek ini dikatakan baik. Salah satu pertimbangan kepraktisan yakni dilihat dari aspek kemudahan penggunaan (Kustandi, C. \& Sutjpto, 2013).

Aspek berikutnya yakni aspek bahasa maupun aspek materi. Kedua aspek ini memiliki keterkaitan dalam menggunakan aplikasi blood smart karena peneliti perlu menggunakan bahasa yang mudah dipahami dalam menyajikan materi sistem peredaran darah manusia. Berdasarkan respon guru dan siswa terhadap angket kepraktisan menunjukan bahwa aspek bahasa sudah baik dan mudah dipahami oleh siswa maupun guru. Penyajian teks pada media pembelajaran perlu menggunakan bahasa Indonesia yang baik dan benar agar informasi yang disampaikan mudah dimengerti oleh siswa (Marlini \& Rismawati, 2019). Oleh karena itu, aspek bahasa dapat mendukung kepraktisan dari media aplikasi blood smart.

Aspek materi juga dinilai baik, karena pemaparan materi pada aplikasi blood smart sudah disajikan dengan jelas dan terstruktur agar siswa mudah memahami materi tersebut. Kebenaran substansi materi perlu diperhatikan untuk menghindari kesalahan pemahaman konsep-konsep bagi peserta didik. Ditinjau dari keseluruhan aspek, maka media aplikasi blood smart memiliki tingkat 
kepraktisan tinggi, media dikatakan memiliki tingkat kepraktisan tinggi apabila bersifat praktis, dalam arti mudah digunakan dan memiliki petunjuk yang jelas (Marlini \& Rismawati, 2019; Rusman, 2012).

\section{SIMPULAN}

Aplikasi blood smart sebagai media pembelajaran biologi berbasis android di era revolusi industri 4.0 dinyatakan valid dari aspek media $(95,2 \%)$ dan aspek materi $(87,5 \%)$ serta dinyatakan praktis dari sudut pandang guru $(95 \%)$ dan siswa $(91,8 \%)$. Selanjutnya, aplikasi blood smart dapat digunakan sebagai media pada pembelajaran biologi dan perlu diuji keefektifannya pada pembelajaran biologi melalui penelitian tindakan kelas atau kuasi eksperimen.

\section{UCAPAN TERIMA KASIH}

Ucapan terima kasih disampaikan kepada LP3M UMRAH yang telah memberikan dukungan dalam pelaksanaan penelitian di lingkungan internal dan kepada Kepala Sekolah SMPS Maitreyawira Tanjungpinang yang telah memberikan kesempatan untuk melaksanakan penelitian.

\section{RUJUKAN}

Ahmed, R. R., Salman, F., Malik, S. A., Streimikiene, D., Soomro, R. H., \& Pahi, M. H. (2020). Smartphone use and academic performance of university students: A mediation and moderation analysis. Sustainability (Switzerland), 12(1), 1-28. https://doi.org/10.3390/SU12010439

Almara'beh, H., Amer, E. F., \& Sulieman, A. (2016). Effectiveness of Multimedia Learning Tools in Education. International Journal of Advanced Research in Computer Science and Software Engineering, 5(12), 761-764. Retrieved from www.ijarcsse.com

Amna, M., Wirasasmita, R. H., \& Fathoni, A. (2018). Pengembangan Media Pembelajaran Berbasis Android Pada Mata Kuliah Sistem Operasi Di Universitas Hamzanwadi. EDUMATIK: Jurnal Pendidikan Informatika, 2(1), 1-7. Retrieved from http://e-journal.hamzanwadi.ac.id/index.php/ edumatic/article/view/816

Aprilia, S., Wijaya, A., \& Suryadi, S. (2014). Efektivitas Website Sebagai Media E-Government dalam Meningkatkan Pelayanan Elektronik Pemerintah Daerah (Studi Pada Website Pemerintah Daerah Kabupaten Jombang). Wacana, Jurnal Sosial Dan Humaniora, 17(3), 126-135. https://doi.org/ 10.21776/ub.wacana.2014.017.03.3

Arsyad, A. (2016). Media Pembelajaran. Jakarta: PT Raja Grafindo Persada.

Asikin, N. (2016). Pembelajaran Biologi Berpendekatan Saintifik Model Sains Teknologi. Pedagogi Hayati, 01(01), 1-10. https://doi.org/https://doi.org/10.31629/ph.v1i1.32

Asikin, N. (2018a). Development Audio-Visual Learning Media of Hydroponic System on Biotechnology Topic For Senior High Schools, 174(Ice 2017), 197-201. https://doi.org/10.2991/ice-17.2018.44

Asikin, N. (2018b). Media Pembelajaran Berbasis Web Pada Mata Kuliah Biologi Sel: Kajian Dari Aspek Validitas. Pedagogi Hayati, 2(1), 33-37. https://doi.org/10.31629/ph.v2i1.271

Evriyanti, T., Muhartati, E., \& Irawan, B. (2019). Profil Media Pembelajaran di SMP Negeri SeKecamatan Tanjungpinang Timur. Pedagogi Hayati, 3(1), 34-43. https://doi.org/10.31629/ ph.v3i1.1125

Hidayati, N., \& Irmawati, F. (2019). Developing Digital Multimedia of Human Anatomy and Physiology Material Based on STEM education. JPBI (Jurnal Pendidikan Biologi Indonesia), 5(3), 497-510. https://doi.org/10.22219/jpbi.v5i3.8584

Hidayati, N., Irmawati, F., \& Prayitno, T. A. (2019). Peningkatan Keterampilan Berpikir Kritis Mahasiswa Biologi Melalui Multimedia STEM Education. JPBIO (Jurnal Pendidikan Biologi), 4(2), 84-92. https://doi.org/10.31932/jpbio.v4i2.536

Hidayati, N., Pangestuti, A. A., \& Prayitno, T. A. (2019). Edmodo Mobile : Developing E-module on Biology Cell For Online Learning Community. Biosfer: Jurnal Pendidikan Biologi, 11(2), 78-89. 
https://doi.org/10.21009/biosferjpb.v11n2.90-100

Kustandi, C. \& Sutjipto, B. (2013). Media Pembelajaran Manual dan Digital. Bogor: Ghalia Indonesia.

Kuswanto, J., \& Radiansah, F. (2018). Media Pembelajaran Berbasis Android Pada Mata Pelajaran Sistem Operasi Jaringan Kelas XI. Jurnal Media Infotama, 14(01), 15-20. https://doi.org/10.32332/an-nabighoh.v20i01.1131

Marlini, C., \& Rismawati (2019). Praktikalitas Penggunaan Media Pembelajaran Membaca Permulaan. Jurnal Tunas Bangsa, 6(2), 277-289. Retrieved from https://tunasbangsa.stkipgetsempena.ac.id/? journal=home\&page=article\&op=view\&path $\% 5 B \% 5 D=142$

Muhaimin, M., Habibi, A., Mukminin, A., Saudagar, F., Pratama, R., Wahyuni, \& Indrayana, B. (2019). A sequential explanatory investigation of TPACK: Indonesian science teachers' survey and perspective. Journal of Technology and Science Education, 9(3), 269-281. https://doi.org/10.39 26/jotse.662

Nazar, M., Putri, R. I. C., \& Puspita, K. (2020). Developing an android-based game for chemistry learners and its usability assessment. International Journal of Interactive Mobile Technologies, 14(15), 111-124. https://doi.org/10.3991/IJIM.V14I15.14351

Nevrita, Asikin, N., \& Amelia, T. (2020). Analisis Kompetensi TPACK pada Media Pembelajaran Guru Biologi SMA. Jurnal Pendidikan Sains Indonesia (Indonesian Journal of Science Education), 8(2), 203-217. https://doi.org/10.24815/jpsi.v8i2.16709

Pranata, M. A., Santyadiputra, G. S., \& Sindu, I. G. P. (2017). Rancangan Game Balinese Fruit Shooter Berbasis Virtual Reality Sebagai Media Pembelajaran, 6, 256-270. https://doi.org/http:// dx.doi.org/10.23887/janapati.v6i3.11994

Prasojo, L. D., Habibi, A., Mukminin, A., Muhaimin, Taridi, M., Ikhsan, \& Saudagar, F. (2017). Managing digital learning environments: Student teachers' perception on the social networking services use in writing courses in teacher education. Turkish Online Journal of Educational Technology, 16(4), 42-55.Retrieved from https://eric.ed.gov/?id=EJ1160635

Prayitno, T. A., \& Hidayati, N. (2017). Pengembangan Multimedia Interaktif Bermuatan Materi Mikrobiologi Berbasis Edmodo Android. Bioilmi: Jurnal Pendidikan, 3(2), 86-93. https://doi.org/10.19109/bioilmi.v3i2.1399

Riyanto, \& Susilawati, L. (2019). Penerapan Media Aurora Animasi 3D Maker Untuk Meningkatkan Hasil Belajar Kognitif Mahasiswa Biologi IKIP Budi Utomo Malang. Edubiotik : Jurnal Pendidikan, Biologi Dan Terapan, 4(01), 52-56. https://doi.org/10.33503/ebio.v4i01.438

Rusdi, M. (2018). Penelitian Desain Dan Pengembangan Kependidikan: Konsep, Prosedur, Dan Sintesis Pengetahuan Baru. Depok: Raja Grafindo Persada.

Rusman. (2012). Belajar dan Pembelajaran Berbasis Komputer. Bandung: Alfabeta.

Sadikin, A. (2019). Interactive Media Development of E-Learning in Welcoming 4 . 0 Industrial Revolution On Ecosystem Material for High School Students Pengembangan Media E-Learning Interaktif Dalam Menyongsong Revolusi Industri 4 . Jurnal IImiah Pendidikan Biologi, 5(2), 131138. https://doi.org/10.22437/bio.v5i2.7590131

Saputro, R. E., \& Saputra, D. I. S. (2014). Pengembangan Media Pembelajaran Mengenal Organ Pencernaan Manusia Menggunakan Teknologi Augmented Reality. Jurnal Buana Informatika, 6(2), 153-162. https://doi.org/https://doi.org/10.24002/jbi.v6i2.404

Stamer, I., Pönicke, H., Tirre, F., Laherto, A., Höffler, T., Schwarzer, S., \& Parchmann, I. (2020). Development \& validation of scientific video vignettes to promote perception of authentic science in student laboratories. Research in Science \& Technological Education, 38(2), 168-184. https://doi.org/10.1080/02635143.2019.1600491

Wabula, M., Papilaya, P. M., \& Rumahlatu, D. (2020). Pengaruh model pembelajaran discovery learning berbantuan video dan problem based learning terhadap motivasi dan hasil belajar siswa. Edubiotik: Jurnal Pendidikan, Biologi Dan Terapan, 5(01), 29-41. https://doi.org/10.33503/ ebio.v5i01.657 
Yektyastuti, R., \& Ikhsan, J. (2016). Pengembangan Media Pembelajaran Berbasis Android pada Materi Kelarutan untuk Meningkatkan Performa Akademik Peserta Didik SMA Developing Android-Based Instructional Media of Solubility to Improve Academic Performance of High School Students. Jurnal Inovasi Pendidikan IPA, 2(1), 88-99. https://doi.org/10.21831/jpi.v2i1.10289 